\title{
Practice of Teaching Reform on Case Based Teaching of Chemical Technology Facilitated by Production Practice
}

\author{
Xiao-ling $\mathrm{ZHAO}^{1}$, Yu-qi WANG ${ }^{2 *}$ \\ ${ }^{1}$ College of Chemistry and Chemical Engineering, Xi'an University of Science and Technology, Xi'an, China \\ ${ }^{2}$ School of Chemical Engineering, Northwest University, Xi'an, China \\ *Corresponding author \\ Mobile +86 13488210810, Fax +86 5108522 5940, E-mail youngtinkling@126.com
}

\begin{abstract}
Since grade 2014, the new teaching plan was carried out that the production practice was put in the middle of the semester. Production practice well planned and was blended with Chemical Technology classroom teaching, students studying effect has quite much improved. Therefore, the teaching team adjusted this new teaching methods. This kind of blended learning and teaching method, which have the chemical Technology teaching extended from the classroom to the production practice site, make students learn to analyze the similarities and differences of the classic process and actual mill process, and help them to research chemical process and write detail summary report, and do the group discussion. By this method, teachers can give score to students by their daily studying and practice, also help teacher to make statistical analysis of the scoring rate for the process analysis questions in the final examination, and make evaluation of the blended teaching methods.
\end{abstract}

Key words: Chemical Technology, Case based teaching, Blended learning, Innovation ability

\section{Preface}

Chemical Technology is a major course for undergraduates who are majoring in chemical engineering[1]. It takes the basic principle and process flow as well as main equipment together in the process of production from raw materials to chemical products as the object of study. The authors found that students always scored poorly on the process analysis questions in the final examination. Production practice is an important practical phase in chemical engineering subjects, but the long-term practice showed the following drawbacks: too many students and mill site noise makes the listening effect not good; students can only draw a flow chart, and the technology principle learned very little.

We found that teaching reform on case based teaching Chemical Technology combine with production practice got win-win effect; By further improve the chemical technology performance evaluation method, it bring the results which be able to more reflect the students' innovation ability, and the ability of solve practical problems; By training of students' ability to collaborate with people, ask questions to company's technician, Students get familiar with the future demand in the job market, and also how to further improve their personality and improve their professional level[2].

\section{Method and Feature of Case Based Teaching}

\section{A. Research Topics:}

The first step, each team is facing topic selection, the mill for students' production practice may provide internship opportunities in several production lines, which may also contain a lot of sections in the whole process, so students have to do a lot of research work in order to check the information before they select section of the whole process, the correct selection will help them to get enough documentation and easy for finish their homework. This process is a learning phase, which request students to have a good number of thoughts before going into the factory. In this process, the students' ability to formulate plans is trained[3].

\section{B. The Live Consult:}

In the past practice, because it is much noisy at mill site, so only a few students always ask questions to the mill master at any time, but many students are always silent. Now with the task to the mill site, the target is clear a lot to students, which inspire them to ask questions actively to the masters. At the same time, students' ability to communicate with people is trained.

\section{A Written Report:}

Report made in school after the production practice, it is a good review of knowledge students learned, also a training of students' ability to analyze and summarize the problems.

\section{Cooperation and Win-win mindset:}

Each topic needs a group of students to finish it together, and everyone needs to prepare their presentation, so that under the pressure of responsibility and pressure, everyone will work hard for the topic with team members, and some students who took back seats are also driven forward. In the process of internship, students can cooperate with each other to develop their team cooperation and innovation ability.

\section{Case based teaching examples}

\section{A. Case 1: Solving Practical Engineering Problems with Mathematical Knowledge:}


When a group of students practiced in an ammonia factory, the technicians and workers in the workshop asked them such a question: there is a liquid ammonia tank in the workshop, the diameter of the middle cylinder is 1.6 meters, and the ends of the cylinders are spherical coronal. The tank is normally placed horizontally, and the current liquid level meter is marked only by its level height, and the unit for height is centimeter. But generally, the factory used to measure liquid ammonia in tonnes, and therefore directly read scale meter cannot directly know the tonnage of liquid ammonia, this caused great inconvenience to the worker's operation. A schematic diagram of the structure of a liquid ammonia tank is shown in Fig.1.

As we all know, in fact, if we know that with the change of the height of the liquid level, and how the volume of the liquid ammonia amount in the tank can be changed, then the weight of the liquid ammonia can be known. Though the problem seems simple, but it is a double integral problem. When we ignore the spherical volume, the length of the tank down as L; from the ground level, denoted as h. Obviously, $h \in[0,0.8]$ and $h \in[0.8$, 1.6], the tank is a symmetric structure, when calculated under the tank volume, on the volume of the tank can be easily got. So, the following tank volume calculation as an example to illustrate: now the problem is reduced to a single variable integral problem (such as shown in (1)), but also because the integrand form complex, therefore by means of analytical integrals almost impossible, so we teachers and students to discuss, put the problem into numerical integration the form of the solution (such as shown in (2)).

$$
\begin{aligned}
& \mathrm{V}=\int_{0}^{\mathrm{h}} 2 \mathrm{x} \cdot \sqrt{\mathrm{r}^{2}-(\mathrm{r}-\mathrm{h})^{2}} \cdot \mathrm{L} \cdot \mathrm{dh} \\
& \mathrm{V}_{\mathrm{i}}=2 \mathrm{xL} \cdot \sum_{1}^{\mathrm{i}} \sqrt{\mathrm{r}^{2}-\left(\mathrm{r}-\mathrm{h}_{\mathrm{i}}\right)^{2}} \cdot \Delta \mathrm{h}
\end{aligned}
$$

After establishing the algorithm of numerical integration, we sent two students to calculate by computer, and calculated 800 data points with two millimeters as the step size. Finally, we successfully printed out a data table corresponding to the liquid level and the weight of liquid ammonia. With this data, the factory's masters made a variable scale meter, which help a lot to the operators for the liquid level control. As a result, the factory's masters gave high praise to our students. The students were greatly encouraged and deeply aware of the practical value of theoretical knowledge applied, and which inspired everyone's enthusiasm for learning.

\section{B. Case 2: The Learning Process Organizing and Optimization Based on the Practical Process of the Factory:}

When we were practicing in a urea plant, we came to a gas purification workshop. The main task of the purification workshop is to provide pure hydrogen raw materials for ammonia, which is mainly to remove sulfide from hydrogen and decarbonization. Due to the plant target to increase the economic benefit, they decide to use coal with rich sulfide for production, since the organic sulfur content is high, which means that the desulfurization equipment is difficult to meet the production needs in future. The factory staff asked us if we have an approach to solve the problem. The teacher who led for chemical technology professional teaching are quite familiar with the desulfurization process, the desulfurization method is currently used is wet oxidation method, and this method mainly used for removal of inorganic sulfur. If we want to get organic sulfur removed, the teacher proposed to add a Co Mo hydrogenation reactor in the process and which should be placed before removal of inorganic sulfur. The proposed reactor is designed to make the organic sulfur is transformed into inorganic sulfur, then factory can continually use of wet oxidation for removal of inorganic sulfur. The workshop team carefully recorded this technology, and they think it will be used for discussion with their design department for the rebuilding. Based on the teaching practice, teachers further discussed with the students what are the common desulphurization processes, the applicable conditions and occasions of every technology and so on, which strengthened the innovative ability of students to solve problems at mill site[1].

\section{Case 3: Understanding of Relationship among Process} Conditions control, Safety Production and Environmental Protection in Production Practice:

Polypropylene is one of the fastest developing products in synthetic resins. At present, most of the domestic production is a continuous liquid phase bulk polymerization process. The analysis of the dangerous factors of the liquid phase bulk production of polypropylene is the core for learning and mastering of the process[4].

When we practiced in one of the polypropylene plant which belong to company of Sinopec, we happened to meet the mill re-start up the production line after the it overhauled. The workshop staff invited our students to see the whole process of start-up. In real time, we have observed a series of dynamic processes such as the process of raw materials input, and the input of catalysts, activators, the heating and boosting of reaction systems, and the product discharge etc. In the process of practice, it is profoundly realized that control for ring reactor temperature is one of the most critical control points in all control devices. If the ring reactor temperature fluctuates a lot or fluctuates for a long time, it will bring bad effects on the long period and stable operation of the device.

Through the learning of actual device operation, we found that the main factors affecting the temperature of the ring reactor are as follows:

1). The raw material of catalyst harmful components content; 2) adding the main catalyst and the catalyst; 3) the amount of hydrogen in the ring reactor; 4) the heat exchanging capacity of the heat exchanger and the actual operation; 5) temperature, flow and quality of the circulating water; 6) the injection amount of carbon monoxide which is polymerization reaction terminating agent[5].

The factors that affect the temperature control of the polymerization reactor have different effects by control of the polymerization reaction temperature because of its different degree of influence. In actual production, the temperature control range of the ring reactor is usually $68-72{ }^{\circ} \mathrm{C}$. If the reactor temperature rises rapidly, it is necessary to look up the reason immediately and take corresponding measures to avoid the reactor's temperature rising fast.

Cooling measures in common are: 1). manual adjustment of control valve for sandwich layer water temperature, turn on the 
cold-water control valve and turn down hot-water control valve, reduce the water temperature in sandwich layer, improve the thermal efficiency of the temperature lowering; 2). increase the ring pipe feed for propylene, with plenty of cold propylene washing, reduce the reactor slurry temperature; 3 ) reduce or stop the hydrogen amount entering the reactor; 4). decreasing or cut off the adding for main catalyst; 5). if the above methods still can't solve the problems, then inject the reaction termination agent $\mathrm{CO}$ to terminate the reaction. In the above control measures, injection of $\mathrm{CO}$ termination agent into reactor is the most effective way to control temperature. However, when $\mathrm{CO}$ is injected into reactor, it will cause temporary shutdown of the device, so this method can be used only when the device is in critical condition.

Through the learning of this process case, students further realized the complicated relationship among the process conditions and chemical safety, environmental protection and economical benefit, and further understood that chemical process is a systematic project.

\section{Established Scientific Evaluation System for Teaching Effect}

\section{A. Explored the Win-win Effect of Theoretical and Practical Teaching.}

In the case based teaching of Chemical Technology facilitated by production practice, we explored the teaching method of integrating the learning process of classical chemical technology into production practice, and through this teaching method study, it will help to promot the practice of chemical technology teaching and production practice teaching each other.

\section{B. Improved the Rating Method for Students' Study Score in} Daily life, Final Term of the "Chemical Technology" Study.

A. Transformed from the past pure online searching documentation to the theory study and the mill site practice for students to finish their big homework. B. Changed from classroom examination to group presentation for rating student's final term score. This made the score rating is closer to the teaching goal of the course of Chemical Technology.

\section{Acknowledgement}

This work was funded by the Teaching Reform Funding from Shaanxi Province (No.15BY27. "The exploration and practice of the construction of the information system of the main courses of chemical engineering major in Shaanxi province")

\section{References}

[1] Mi Zhen Tao. Chemical Technology[M]. Bei Jing: Chemical Industry Press, 2006.

[2] Wang Zhen. The analyses on the teaching reform in chemical technology subject [J]. Journal of Anhui University of Science and Technology (Social Science), Dec.2007,9(4):66-68.

[3] Hu Yulin. Teaching Practice and Exploration on the Chemical Engineering Technology Under the Concept of Green Chemistry [J]. Shandong Chemical Industry, 2015, 44(16): 164-165.

[4] Sun Dao Hua \&Li Qing Biao, Teaching Practice and Innovation in Chemical Technology [J]. Higher education of Chemical
Engineering, 2007, (5):92-94.

[5] Geng Shuai. Hazardous Factors Analysis and Safety Measures in the Production of Polypropylene[J]. Safety Technology, 2008, 8(7): 19-20.

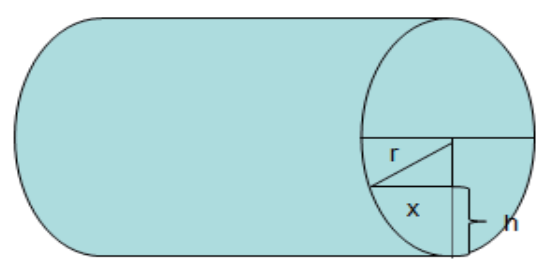

Fig. 1 Schematic diagram of the structure of liquid ammonia tank 
Recent Developments on Information and

Communication Technology (ICT) Engineering- Meen, Yang \& Zhao ISBN: 978-981-14-2136-5 